\title{
Reumatologia 2008
}

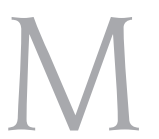

ais um ano se inicia, com novas promessas de que a nossa especialidade vai continuar em seu processo de marcada transformação iniciado já há aproximadamente uma década. O desenvolvimento de novas estratégias terapêuticas levou a uma inegável melhora nos desfechos de uma parcela significativa dos nossos pacientes - aqueles com artrites inflamatórias crônicas. O progresso realmente tem sido surpreendente, com a aprovação de pelo menos seis agentes biológicos para o tratamento desses pacientes. Um grande número de novos fármacos encontra-se em diversas fases de desenvolvimento clínico, incluindo novas abordagens para o manejo do lúpus eritematoso sistêmico. Avanços recentes na identificação de marcadores genéticos de suscetibilidade também abrem o caminho para nova gama de potenciais alvos terapêuticos a serem explorados, bem como para a sonhada "personalização" da terapêutica por meio da farmacogenética.

Essa situação provoca grande entusiasmo e otimismo entre a comunidade reumatológica internacional, sentimentos claramente evidenciados durante os nossos eventos científicos. Entretanto, acreditamos que esses sentimentos devam ser moderados diante do número de desafios importantes que ainda precisamos enfrentar caso não desejemos que a nossa especialidade perca espaço e oportunidades em uma prática médica cada vez mais competitiva e direcionada por questões de custo-efetividade. Mencionamos a seguir alguns desses desafios que têm chamado a nossa atenção particular.

Apesar dos sucessos destacados acima, permanecem dificuldades relacionadas aos desenhos dos ensaios clínicos que vêm sendo empregados para a aprovação de novos fármacos para as artrites crônicas. Esses ensaios são baseados na tentativa de estabelecer eficácia dos novos agentes em pacientes em que tenham "falhado" terapias atuais (essencialmente o metotrexato, cujo exato mecanismo de ação permanece desconhecido). A dificuldade com essa abordagem, bastante visível para aqueles com experiência na condução de estudos clínicos multicêntricos, é que os critérios de inclusão são cada vez mais restritivos, resultando que os pacientes efetivamente avaliados são pouco representativos da nossa prática clínica. Além disso, com a disseminação do uso dos biológicos, o número de pacientes selecionáveis para esses estudos vai se tornar cada vez menor e representará um subgrupo com doença muito resistente. Portanto, devemos buscar o desenvolvimento de novas metodologias para o desenho de estudos, por exemplo, direcionados especificamente à remissão/cura da doença, talvez empregando estratégias mais inovadoras e corajosas, como o uso combinado ou seriado de imunobiológicos.

Outro grande desafio é o desenvolvimento lento do progresso em algumas das nossas doenças mais comuns e debilitantes, especialmente a osteoartrite, que se tem mostrado como um enorme desafio. Sua patogênese permanece obscura, modelos adequados são inexistentes e ainda engatinhamos no desenvolvimento de biomarcadores, apesar de algumas promessas. Diante do número crescente de pacientes por conta da maior longevidade, nós infelizmente ainda não temos muito a oferecer além de uma avaliação informada dos riscos e benefícios do uso de antiinflamatórios não-hormonais.

Uma doença que também merece ser destacada é a fibromialgia, com a qual o desenvolvimento científico sofre em parte em virtude das incertezas quanto à validade desse diagnóstico, bem como de nosso papel na abordagem desses pacientes. Apesar dessas incertezas, acreditamos que os reumatologistas devem manter sua liderança na formulação de questionamentos e condução das pesquisas, aproveitando os desenvolvimentos recentes nas áreas de neurobiologia $\mathrm{e}$ neuroimagem. Nesse sentido, vale destaque ao artigo de Ribeiro Sobrinho e cols. neste número da nossa revista, em que novas estratégias para avaliação da sonolência nesses pacientes são exploradas.

A abordagem desses desafios deve ser corajosa, o que não significa que devamos esquecer os riscos envolvidos, como o risco de infecções com as estratégias de imunomodulação. Aqui, destacamos, neste número, o trabalho de Sousa e cols. chamando a atenção para a questão da tuberculose renal em pacientes com lúpus.

Em suma, neste ano de 2008 certamente teremos muito a comemorar, mas não devemos perder de vista que ainda temos muito para aprender e fazer. Devemos manter os esforços para que a nossa Revista Brasileira de Reumatologia continue e se aprimore no papel de veículo de estímulo e divulgação dos esforços nacionais de enfrentamento desses desafios.

Francisco Airton Castro da Rocha Ricardo Machado Xavier Editores científicos 